\title{
White matter pathways mediate parental effects on children's reading precursors
}

Vandermosten Maaike, Cuynen Lieselore, Vanderauwera Jolijn, Wouters Jan, Ghesquière Pol

\section{Corresponding author:}

Maaike Vandermosten, L. Vanderkelenstraat 32, PO Box 3765, 3000 Leuven, Belgium.

Tel.: +32 163262 94, Fax: +32 1632 59 33, Maaike.Vandermosten@kuleuven.be 


\begin{abstract}
Previous studies have shown that the link between parental and offspring's reading is mediated by the cognitive system of the offspring, yet information about the mediating role of the neurobiological system is missing. This family study includes cognitive and diffusion MRI (dMRI) data collected in 71 pre-readers as well as parental reading and environmental data. Using sequential path analyses, which take into account the interrelationships between the different components, we observed mediating effects of the neurobiological system. More specifically, fathers' reading skills predicted reading of the child by operating through a child's left ventral white matter pathway. For mothers no clear mediating role of the neural system was observed. Given that our study involves children who have not yet learned to read and that environmental measures were taken into account, the paternal effect on a child's white matter pathway is unlikely to be only driven by environmental factors. Future intergenerational studies focusing on the genetic, neurobiological and cognitive level of parents and offspring will provide more insight in the relative contribution of parental environment and genes.
\end{abstract}

\title{
Keywords
}

Reading; diffusion MRI; Family risk; parental reading; pre-readers; neural mediation 


\section{Introduction}

Dyslexia is a disorder characterized by severe and resistant reading and spelling difficulties that cannot be explained by factors such as lack of motivation, sensory deficits or inadequate schooling (Snowling, 2000; Vellutino, Fletcher, Snowling, \& Scanlon, 2004). According to contemporary views, the origin of dyslexia is multifactorial, meaning that is not caused by one etiological factor, but rather by a complex interaction between several cognitive, neurobiological, environmental and genetic factors (Pennington et al., 2012; Peterson \& Pennington, 2015). The cognitive and neurobiological factors are assumed to mediate genetic contributions to reading. An extension of this model is the intergenerational model of van Bergen, van der Leij, \& de Jong (2014), which emphasizes the role of both parents in influencing children's reading outcome via intertwined genetic and (home) environmental factors. Our study will investigate how cognitive and neurobiological factors mediate parental influences on reading, and examine the contribution of environmental factors.

Although the presumed intermediaries are still largely unknown, different lines of evidence support parental influences on children's reading. First, support is found in family risk studies, generally consisting of a group of children with a family risk for dyslexia, based on having a first-degree relative (often a parent) diagnosed with dyslexia, and a group of children without a family risk for dyslexia. These studies show that family risk children, have a chance of 40 to $60 \%$ to ultimately develop dyslexia instead of 5 to $7 \%$ chance in the typical population (Peterson \& Pennington, 2015; Scerri \& Schulte-Körne, 2010). Second, although less severe than dyslexic children, non-dyslexic family risk children also exhibit subtle difficulties in literacy and phonological skills relative to non-dyslexic children without a family risk (for a review see Snowling \& Melby-Lervåg, 2016). Especially phonological awareness (PA) (i.e. the ability to manipulate speech sounds) and, to some extent, rapid automatized naming (RAN) (i.e. the ability to rapidly retrieve verbal information in response to visual stimuli) have been shown to be associated with reading ability of the child as well as with familial history of reading problems (Moll, Loff, \& Snowling, 2013; for a review see Snowling \& Melby-Lervåg, 2016). Third, studies that more precisely capture the specific role of parents demonstrated weaker phonological skills in parents of dyslexic children than in parents of non-dyslexic children (van Bergen, Jong, \& Plakas, 2012; van Bergen, Jong, Regtvoort, \& Oort, 2011). These parent-offspring associations were found irrespective of whether the parent was diagnosed with dyslexia or was unaffected, suggesting again parental effects on children's reading performance (van Bergen, de Jong, Maassen, \& van der Leij, 2014). Finally, a recent study provided direct evidence that cognitive skills mediate the parent-offspring associations for reading (van Bergen, Bishop, van Zuijen, \& de Jong, 2015). Importantly, in that study not all parental influences on children's reading were mediated by cognitive skills, hence these might be 
explained by neurobiological and environmental factors that were not taken into account. Based on the intergenerational multiple deficit model (van Bergen, van der Leij, et al., 2014), the neurobiological system of the child is indeed assumed to mediate the link between parental and a child's reading.

Concurrent evidence from MRI studies has indicated that reading engages a left-lateralized network of inferior frontal, temporo-parietal, and occipito-temporal regions, with dyslexic readers showing anomalies in the latter two regions (Paulesu, Danelli, \& Berlingeri, 2014; Richlan, Kronbichler, \& Wimmer, 2009, 2013). These distant brain regions are connected through white matter pathways that enable an efficient communication between them. By means of diffusion MRI (dMRI) white matter organization in these pathways can be quantified. Two white matter fiber tracts seem particularly important for reading in pre-readers, schoolaged children and adults; i.e. the dorsally running arcuate fasciculus (AF) which is predominantly involved in reading (Myers et al., 2014; Rimrodt, Peterson, Denckla, \& Kaufmann, 2010; Steinbrink, Vogt, Kastrup, \& Müller, 2008), phonological processing (Saygin et al., 2013; Vanderauwera, Vandermosten, Dell'Acqua, Wouters, \& Ghesquière, 2015; Vandermosten et al., 2012, 2015; Yeatman et al., 2011) and grapheme-phoneme coupling (Gullick \& Booth, 2014) and the ventrally running inferior fronto-occipital fasciculus (IFOF) which is predominantly involved in reading (Odegard, Farris, Ring, McColl, \& Black, 2009; Steinbrink et al., 2008), orthographic processing (Vandermosten et al., 2012), and in prereaders also in phonological processing (Vandermosten et al., 2015). Although no direct evidence is available on the mediating role of children's neurobiological system, recent MRI studies in pre-readers with and without a family risk might be of interest. These studies indicate that some of the anomalies observed in individuals with dyslexia are also present in prereaders with a family risk for dyslexia, regardless of their reading outcome (for a review see Ozernov-Palchik \& Gaab, 2016). More specifically, family risk seems to be reflected in the prereading brain at the structural (Black et al., 2012; Im, Raschle, Smith, Grant, \& Gaab, 2016; Raschle, Chang, \& Gaab, 2011), functional (Raschle, Zuk, \& Gaab, 2012) and connectivity level (Hosseini et al., 2013; Vandermosten et al., 2015). Anomalies related to the family risk are located within the typical reading network, including left temporo-parietal (Black et al., 2012; Hosseini et al., 2013; Raschle et al., 2011, 2012) and left occipito-temporal regions ( Raschle et al., 2011, 2012), as well as some anomalies located in the right hemisphere (Black et al., 2012; Raschle et al., 2012) and cerebellum ( Raschle, Stering, Meissner, \& Gaab, 2014; Raschle et al., 2012) (for a meta-analysis on MRI-studies in pre-readers see Vandermosten, Hoeft, \& Norton, 2016). However, to our best knowledge, none of these MRI-studies has clearly dissociated the neural patterns associated with family risk, cognitive risk and eventual reading 
problems. Hence, they lack a precise modeling of the directed dependencies of the neurobiological system with these risk factors and reading.

The observed familial influences on children's reading ability are generally interpreted as genetic influences, supported by studies showing that genes explain about $60 \%$ of the individual differences in reading ability (Olson, Keenan, \& Byrne, 2014). Furthermore, while a relation is observed between biological parent-offspring reading skills, no clear relation is observed between parent-child in adoption families (Wadsworth, Corley, Hewitt, Plomin, \& DeFries, 2002). Although this suggest a strong genetic contribution in the parental influences on children's reading, parents also influence their children's reading skills through the environment they provide. One of the environmental factors that is determined by the parents is home literacy environment (HLE), such as the numbers of books at home or the amount of shared reading. Although HLE does not explain why reading-related differences are observed between FRD ${ }^{+}$and FRD- children (Hosseini et al., 2013; Snowling, Muter, \& Carroll, 2007; Elsje van Bergen, de Jong, et al., 2014), it is associated with reading-related skills in kindergarten as well as with later reading (Molfese, Modglin, \& Molfese, 2003; Sénéchal \& LeFevre, 2002; Silinskas, Lerkkanen, Tolvanen, \& Niemi, 2012; Torppa, Poikkeus, \& Laakso, 2006). Other environmental factors such as socio-economic status (SES) have also been indicated to be relevant for reading development (Niklas \& Schneider, 2013) and its neural correlates (Noble, Wolmetz, Ochs, Farah, \& McCandliss, 2006).

The overall aim of this study is to investigate whether and how children's cognitive and neuroanatomical system mediates parental impact on children's reading ability. There are three different models that can underlie the relationships between parental reading skills and children's early reading scores (van Bergen et al., 2015) (see Figure 1). The first model, the additive model, is a model in which parental influences, children's neurobiological system and children's cognitive system are considered as independent factors. These independent factors additively impact on children's early reading score. Second, the full mediation model considers children's neurobiological system and children's cognitive system as the only link between parental influences and children's early reading score. The partial mediation model is a model in which children's neurobiological and cognitive system only partly mediate parental influences on children's early reading score, and this model has been found to be the best fit for the cognitive system (van Bergen et al. 2015). We will assess parental influences via parental reading performance and via environmental measures such as HLE and SES. Reading skills of the child are assessed by letter knowledge in grade 1 and by later reading scores in grade 2. The cognitive and neuroanatomical system of the child is assessed in the last year of kindergarten. In Flemish schools, no formal reading instruction is given in kindergarten (http://www.ond.vlaanderen.be/), which implies that kindergarten children can 
generally not yet read words. By investigating the most relevant white matter tracts for reading, i.e. AF and IFOF, together with the cognitive assessment of phonological skills, we aim to better capture the intermediate levels that might mediate the link between parental influences and a child's reading outcome.

Figure 1. Representation of the three different models. The blue and orange arrows indicate the relationships that could disappear respectively in the full mediated model and the additive model. The full lines represent direct links between parental influences and child's reading whereas the dotted lines represent indirect effects.

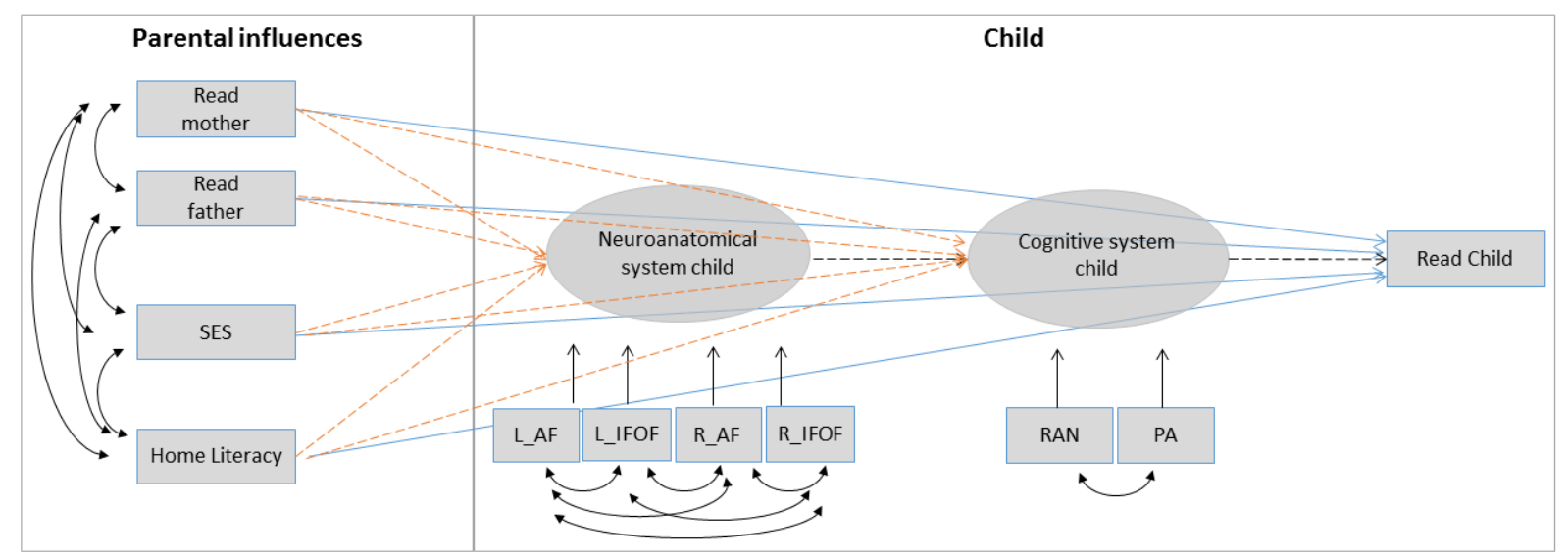

\section{Method}

Table 1 provides descriptive statistics and number of participants for each of the tests and questionnaires administered in parents and children. It also contains FA for each of the delineated white matter tracts in children. More details on the cognitive and diffusion MRI measures administered in the children can be found in Vandermosten et al. (2015).

Table 1: Descriptive statistics of children's and parental cognitive and reading skills and children's neuroanatomical measures

\begin{tabular}{|c|c|c|c|c|c|}
\hline & $\mathrm{N}$ & Minimum & Maximum & Mean & $\begin{array}{c}\text { Std. } \\
\text { Deviation }\end{array}$ \\
\hline \multicolumn{6}{|l|}{ Parental influences } \\
\hline Home Literacy Environment & 62 & 27 & .90 & .49 & 13 \\
\hline Socio-Economic Status & 69 & 2.00 & 8.00 & 5.43 & 1.60 \\
\hline Maternal ARHQ & 66 & .06 & .71 & .31 & .15 \\
\hline Maternal word reading a & 56 & 51.0 & 116.0 & 88.6 & 14.4 \\
\hline Maternal pseudo-word reading a & 56 & 20.0 & 115.0 & 86.3 & 20.3 \\
\hline Maternal composite reading score ${ }^{a}$ & 56 & -2.57 & 1.56 & 1.79 & 0.93 \\
\hline Paternal ARHQ & 64 & .08 & .89 & .34 & .16 \\
\hline Paternal word reading ${ }^{\text {a }}$ & 32 & 63.0 & 116.0 & 96.8 & 16.5 \\
\hline Paternal pseudo-word reading a & 31 & 53.0 & 113.0 & 90.2 & 18.6 \\
\hline Paternal composite reading score ${ }^{a}$ & 32 & -1.96 & 1.71 & 0.02 & 0.95 \\
\hline \multicolumn{6}{|c|}{ Neurobiological system of the child (kindergarten) } \\
\hline Right $A F$ a & 50 & .42 & .51 & .46 & .02 \\
\hline
\end{tabular}




\begin{tabular}{lccccc} 
Left AF & 71 & .42 & .55 & .49 & .03 \\
$\quad$ Right IFOF & 71 & .42 & .51 & .48 & .02 \\
$\quad$ Left IFOF & 71 & .43 & .53 & .49 & .02 \\
$\begin{array}{l}\text { Cognitive system of the child (kindergarten) } \\
\text { PA end rhyme }\end{array}$ & 71 & 2.00 & 12.00 & 8.73 & 2.47 \\
$\quad$ PA end phoneme identification & 71 & 0.00 & 10.00 & 4.07 & 2.27 \\
$\quad$ Composite PA score & 71 & -1.84 & 1.75 & .00 & .79 \\
$\quad$ RAN objects & 71 & 0.34 & 1.06 & 0.63 & 0.16 \\
$\quad$ RAN colors & 71 & 0.21 & 0.94 & 0.61 & 0.15 \\
$\quad$ Composite RAN score & 71 & -2.00 & 2.29 & .00 & .94 \\
Early reading index of the child (grade 1) & & & & & \\
$\quad$ LK productive & 71 & 0.00 & 16.00 & 9.56 & 3.99 \\
LK receptive & 71 & 3.00 & 16.00 & 10.39 & 3.66 \\
$\quad$ Composite LK score & 71 & -2.21 & 1.57 & .00 & .97 \\
Reading of the child (grade 2) & & & & & \\
$\quad$ Word reading & 71 & 2.00 & 58.00 & 22.69 & 13.2 \\
Pseudo-word reading & 71 & 3.00 & 49.00 & 17.31 & 9.71 \\
$\quad$ Composite reading score & 71 & -1.52 & 2.89 & 3.49 & 0.97 \\
\hline \hline
\end{tabular}

a these variables are not included in further analyses given the high number of missing data

ARHQ = Adult Reading History Questionnaire; $\mathrm{AF}=$ Arcuate Fasciculus; IFOF = Inferior Fronto-Occipital Fasciculus; PA = phonological awareness; RAN = Rapid Automatized Naming; LK = Letter knowledge

\subsection{Participants}

This study is part of a longitudinal project involving 87 Dutch-speaking children, of whom 75 children participated in an MRI examination. For this study, we analyzed the data of 71 children (41 male, 30 female) in whom diffusion MRI data were successfully collected (same sample as in Vandermosten et al., 2015). Thirty-six children had an elevated family risk for dyslexia, defined as having a first degree relative diagnosed with dyslexia, and 35 had no elevated family risk, defined as no first degree relatives diagnosed with dyslexia. Children with an elevated family risk were recruited by contacting public schools, speech-language therapist and rehabilitations centers over Flanders. The group of children without a family risk were recruited trough the schools of the high risk children. A detailed description and comparison of the group of children with and without an elevated family risk for dyslexia can be found in Vandermosten et al. (2015). Five inclusion criteria were taken into account: (1) a non-verbal IQ above 80, based on the Raven Colored Progressive Matrices (Raven, Court, \& Raven, 1984), (2) normal hearing, defined as a Fletcher index of less than $20 \mathrm{~dB} \mathrm{HL}$, (3) monolingual Dutch speaking, (4) no history of brain damage, long-term hearing loss, vision or articulatory problems, and (5) no high risk for developing ADHD, based on the Strength and Difficulties Questionnaire of ADHD symptoms. Cognitive skills (RAN and PA) and neuroimaging examination (dMRI) were administered in the last year of kindergarten (cognitive data: $M=61.57, S D=3.07$; neuroanatomical data: $M=73.93, S D=3.26$ ). Letter knowledge was assessed at the beginning of grade $1(M=74.28, S D=3.22)$ and word and pseudo-word reading tests were assessed at the beginning of grade $2(M=86.07, S D=3.22)$. The local 
Ethical Board approved this study and the parents of all children gave written consent to participate.

\subsection{Materials}

\subsubsection{Parental influences}

\subsubsection{Parental reading ability}

Parents reading ability was evaluated two ways. First, an adult reading history questionnaire (ARHQ) (Lefly \& Pennington, 2000; Nuytten, 2005) was filled in by more than $90 \%$ of the parents (mothers: $n=66$; fathers: $n=64$ ). This questionnaire measures both the childhood and current reading experiences. Items are scored on a five-point scale. Higher scores indicate more reading problems. When applying the standard cut-off score of .30 to define someone as reading impaired (Lefly \& Pennington, 2000), 58\% of the fathers is affected and $47 \%$ of the mothers. This is expected since half of the participants have a high family risk for dyslexia, defined as having a first degree relative (often a parent) who has a dyslexia diagnosis

Second, in $45 \%$ of the fathers and $79 \%$ of the mothers reading ability was tested by means of standardized word and pseudo-word reading tests (Brus \& Voeten, 1973; K. P. van den Bos, Spelberg, Scheepstra, \& de Vries, 1994). Both reading tests required speeded reading of a list of 116 words/pseudo-words with increasing difficulty. The number of words read correctly was converted into a z-score for each test and averaged to obtain a composite score for reading ability. Given that standardized reading tests were only assessed in a subsample of parents, they will not be used for further analyses. It is however noteworthy that the correlation between the $\mathrm{ARHQ}$ and the composite score of the standardized reading tests was moderate to high in the subsample of parents who conducted both (mothers: $r=-.52, p<.001$; fathers: $r=-.74$, $p<.001$ ), hence the ones who report more reading problems also score lower on the standardized reading tests. This shows that the ARHQ is a valid indication of reading ability in adults.

\subsubsection{Parental environment}

Information about home literacy (HLE) was assessed by a questionnaire that was based on previous HLE questionnaires (Torppa, Poikkeus, \& Laakso, 2007; van Bergen, de Jong, et al., 2014). The parents were asked to estimate the reading frequency and the duration they spent reading together with their child. The frequency items were scored on a five-point scale ("never" to "several times a day"). The duration items were scored on a three-point scale ("less 
than 15 minutes a day" to "more than 45 minutes a day"). HLE questionnaires were completed for 62 of the 71 children.

SES was measured with the Family Affluence Scale. This questionnaire consisted of four items that assessed the material condition of the families. This is assessed by asking about the number of cars in the family, whether children have their own bedroom, whether they went on a vacation during the last year, and how many computers they own. The first item was scored on a scale from 0 to 2 and the last 3 items were scored using a scale from 0 to 3 (Boudreau \& Poulin, 2009; Boyce, Torsheim, Currie, \& Zambon, 2006).

\subsubsection{Neurobiological system of the child}

\subsubsection{Data acquisition}

All participants underwent MRI examination on a 3T scanner (Philips) with a 32-channel head coil. The MRI data were acquired using a single shot echo planar imaging (EPI) with SENSE (parallel) acquisition. DTI sagittal slices were acquired with the following parameters: repetition time $7600 \mathrm{~ms}$, echo time $65 \mathrm{~ms}$, flip angle $90^{\circ}$, voxel size $2.5 \times 2.5 \times 2.5 \mathrm{~mm}, 60$ non-collinear directions, b-value $1300 \mathrm{~s} / \mathrm{mm}^{2}, 6$ non-diffusion-weighted images. To prepare the children for the MRI-scan, the 'submarine' protocol was used (for more information about this protocol and the motion parameters see Theys, Wouters, \& Ghesquière, 2014).

\subsubsection{Data processing}

Pre-processing was done using ExploreDTI (Leemans, Jeurissen, Sijbers, \& Jones, 2009), including rigorous motion and eddy current correction with the required reorientation of the b-matrix and an iterative nonlinear tensor estimation process to generate fractional anisotropy (FA)-maps (Leemans \& Jones, 2009). Next, whole brain deterministic tractography was performed for each individual DTI dataset using a step-size of $2 \mathrm{~mm}$, a FA threshold of 0.2 , an angle threshold of $40^{\circ}$, and a fiber length range of $50-500 \mathrm{~mm}$. The software TrackVis was used to delineate the tracts of interest. We delineated two tracts that have been demonstrated to be related to reading, i.e. the direct segment of Arcuate Fasciculus $\left(A F_{F T}\right)$, connecting Broca's and Wernicke's regions, and the inferior fronto-occipital fasciculus (IFOF) (see Figure 2). Also in the present sample, these two tracts have been demonstrated to be robustly related to phonological skills prior to reading onset whereas this was not the case for the anterior and posterior segment of the arcuate fasciculus (Vandermosten et al., 2015). Delineation was done according to the protocols of Wakana et al. (2007) and Catani \& de Schotten (2012), in which detailed information is given on the anatomical landmarks for placing the appropriate regions-of-interest. An average FA-value along each tract was calculated. We were able to delineate bilateral IFOF and left $A F_{F T}$ in all children, yet the right $A F_{F T}$ was only 
found in 50 of the 71 subjects $(70 \%)$. Given the high number of subjects with a missing right $\mathrm{AF}_{\mathrm{FT}}$, we decided to omit this tract from further analyses, especially since one cannot disentangle whether a missing right $\mathrm{AF}_{\mathrm{FT}}$ represent the anatomical reality of that subject or whether this is due to the limitations of the fiber tracking reconstruction method (Yeatman et al., 2011). To assess inter-rater variability of the included tracts, two raters delineated lefthemispheric tracts, showing a very high correspondence in FA, with concordance correlation coefficient equal to .981 and .977 for the IFOF and $\mathrm{AF}_{\mathrm{FT}}$ respectively. In the present sample of pre-readers, the included tracts have been compared between pre-readers with and without a family risk (Vandermosten et al., 2015), but in the present study we apply a dimensional and integrative approach to investigate the interdependencies between the different levels.

Figure 2. DTI tractography of the direct segment of the left arcuate fasciculus $\left(A F_{F T}\right)$ and the left inferior fronto-occipital fasciculus (IFOF). The right IFOF is also included in the analyses but is not depicted in the figure. The right $A F_{F T}$ is not included in the analyses since it could only be delineated in $70 \%$ of the subjects.

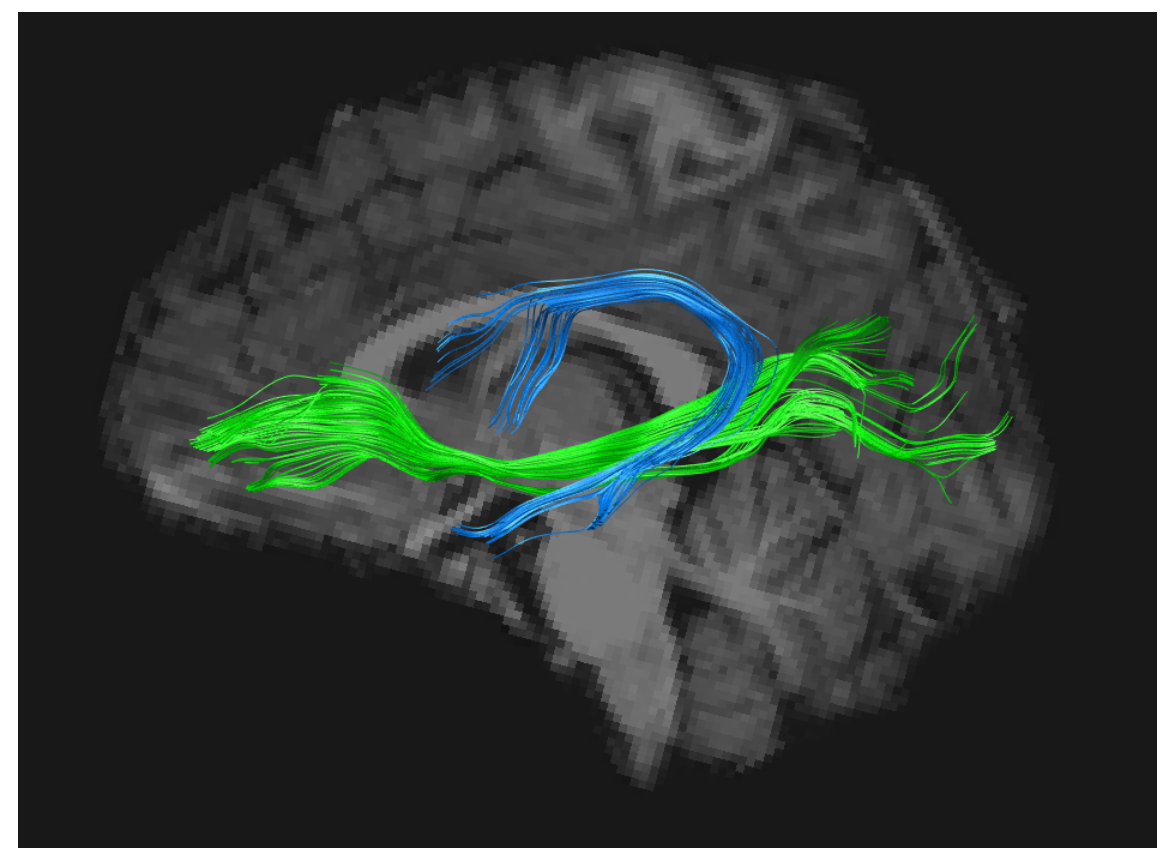

\subsubsection{Cognitive system of the child}

To evaluate phonological skills, children were measured on PA and RAN at the beginning of the last year of kindergarten. PA in children was assessed by an end phoneme and end rhyme identification task (de Jong, Seveke, \& Veen, 2000). These tasks consisted of 12 items in which a high frequent one-syllable Dutch word was presented together with a row of five pictures. The child had to point to the word that contains the same end rhyme or end phoneme as the given word. Performance on both tasks was assessed by the number of 
correct answers (Boets et al., 2010). These scores were converted into a z-score and averaged to obtain a composite score for PA which is used in the statistical analyses.

Naming speed in children was assessed by two RAN tasks, one for objects and one for colors. Each list presents 10 times 5 different stimuli in random order. The child had to name the stimuli as quickly as possible (Boets et al., 2010; van den Bos \& Zijlstra, 2002). Performance on these tasks was assessed by the number of correct answers per second. These scores were also converted into a z-score and averaged to obtain a composite score for naming speed which was used in the statistical analyses.

\subsubsection{Reading skills of the child}

As an early reading index, we used a combination of a receptive and productive letter knowledge (LK) task which was assessed in the children at the beginning of grade 1. In the receptive task, children had to choose the letter that matched with the corresponding sound from six alternatives. In the productive task, children had to name the 16 most frequently used letters in Dutch books. These scores were also converted into a z-score and averaged to obtain a composite score for LK which was used in the statistical analyses (Boets et al., 2010; Verhoeven, 2002).

As a reading ability score, we used a combination of a standardized word and pseudo-word reading test assessed in the beginning of Grade 2. Both of the reading tests required speeded reading of a list of 116 words/pseudo-words with increasing difficulty. The number of words correctly read was converted into z-scores and averaged to obtain a composite score for reading ability (Brus \& Voeten, 1973; K. P. van den Bos et al., 1994).

\subsection{Statistical analyses}

In a first exploratory step, we analyzed which of the pre-reading neurobiological and cognitive measures are related to reading scores of parents and children. Neurobiological and cognitive measures that are correlated to reading scores are considered as putative mediators between parents and offspring and are therefore taken into account in the second step using path analyses. For the correlational analyses, we calculated Pearson correlations except for the data which were not normally distributed (i.e. fathers' ARHQ, HLE as well as composite children's reading score and LK). Given that this was an exploratory step in order to decide which variables are potentially relevant to include in the path analyses, no multiple comparison correction was applied on the correlations. Although correcting for multiple comparisons decreases type I errors, it increases type II errors (Nakagawa, 2004), which in our case could have resulted in a too stringent variable selection for the path analyses. For the path analyses, the complex interdependencies between the different levels of data were modelled. ARHQ 
were inversed transformed so that a higher score indicated a better reading ability. Path analyses were performed to explore how the neuroanatomical and cognitive system of the child mediate the link between parents and children's reading. For the path analyses the potential direct links between parental influences and children's cognitive system are omitted as this resulted in an instable model due to the complexity. This implies that in the tested model the indirect parental influences on children's reading are mediated via the neuroanatomical system that in turn influences the cognitive system. We conducted structural equation modeling (SEM) in SAS via Proc Calis statement. In order to handle missing values, we applied the Full Information Maximum Likelihood method (FIML).

\section{Results}

\subsection{Defining the intermediate neuroanatomical and cognitive measures}

In order to select the variables of the cognitive and of the neurobiological system that could intermediate parental influences on children's reading (see Figure 1), we first explored which of the cognitive and neuroanatomical variables correlated significantly with both children's reading and parental reading (table 2). In a next step (see paragraph 3.2), we will then incorporated the neuroanatomical and cognitive variables for which significant correlations were found into the model, thereby simultaneously taking into account the interdependencies between the different levels (i.e. parental influences, children's neuroanatomical system, children's cognitive system, children's reading skills). The correlation table between all measured variables is provided as supplementary information (Table SI).

The upper part of table 2 provides the correlations between children's reading, i.e. early reading index (LK in grade 1 ) and composite reading score in grade 2, and children's cognitive and neuroanatomical measures. At the cognitive level, children's performance on RAN and on PA correlated significantly with the early reading score index (RAN: $p=.0001$; PA: $p<.001$ ), and with later reading scores (RAN: $p=.005$; PA: $p<.001$ ). At the neuroanatomical level, children's $\mathrm{FA}$ in left $\mathrm{AF}_{\mathrm{FT}}$ did not correlate significantly with the early reading index $(p=.090)$ nor with later reading $(p=.125)$. On the other hand, bilateral IFOF correlated significantly with the early reading index (Left: $p=.026$; Right: $p=.020$ ), though not with later reading scores (Left: $p=.140$; Right: $p=.292$ ). In short, PA, RAN and bilateral IFOF in children show some correlations with children's reading scores.

Table 2: Correlations between children's cognitive and neuroanatomical measures on the one hand children's and parental reading data on the other hand 


\begin{tabular}{|c|c|c|c|c|c|c|}
\hline & & \multicolumn{2}{|c|}{$\begin{array}{c}\text { Cognitive system } \\
\text { child } \\
\text { (kindergarten) }\end{array}$} & \multicolumn{3}{|c|}{$\begin{array}{c}\text { Neuroanatomical system child } \\
\text { (kindergarten) }\end{array}$} \\
\hline & & PA & RAN & $\mathrm{L} \quad \mathrm{AF}_{\mathrm{FT}}$ & L IFOF & R_IFOF \\
\hline \multirow{2}{*}{$\begin{array}{l}\text { Child's } \\
\text { reading }\end{array}$} & Composite LK (grade 1) & $.439^{\star *}$ & $.491^{* *}$ & .203 & $.263^{*}$ & $.276^{*}$ \\
\hline & Composite reading (grade 2 ) & $.330^{* *}$ & $.422^{* *}$ & .184 & .177 & 0.127 \\
\hline \multirow{2}{*}{$\begin{array}{l}\text { Parental } \\
\text { reading }\end{array}$} & ARHQ mother & -.042 & $-.398^{* *}$ & .138 & .023 & -.031 \\
\hline & ARHQ father & $-.257^{*}$ & -.170 & -.099 & $-.295^{*}$ & -.027 \\
\hline
\end{tabular}

The lower part of table 2 provides correlation coefficients between family risk, measured by the parental reading skills questionnaires, and a child's cognitive and neuroanatomical measures. At the cognitive level, ARHQ of mothers correlated significantly with children's RAN $(p=0.001)$, yet not with children's PA $(p=0.737)$. The more mothers reported problems with reading, the lower children scored on RAN. At the neuroanatomical level, no significant correlations were found between ARHQ of mothers and children's neuroanatomical measures (Left AF $\mathrm{FT}_{\mathrm{FT}}: p=0.268$; Left IFOF: $p=0.853$; Right IFOF: $p=0.807$ ). In fathers, the ARHQ significantly correlated with children's PA $(p=0.040)$, yet not with a children's RAN $(p=0.320)$. The more fathers reported problems with reading, the lower children scored on PA. Regarding the neuroanatomical measures, a significant correlation was found between ARHQ of fathers and a child's FA in the left IFOF $(p=0.018)$ yet not with right IFOF $(p=0.86)$ and left $\operatorname{AF}_{\mathrm{FT}}(p$ $=0.30)$. The results indicated that the more reading problems the fathers reported, the higher FA in the children's IFOF. In sum, PA, RAN and left IFOF are to some extent related to family risk, assessed by parental reading data.

Hence, given that PA and RAN correlate with parental as well as children's reading, we will take both into account as part of children's cognitive system in the model for path analyses. For children's neuroanatomical system only left IFOF will be taken into account as this was the only white matter tract that correlated with both parental and children's reading scores.

\subsection{Modeling the relationships of putative neuroanatomical and cognitive mediators}

To explore how the child's neuroanatomical and cognitive system mediates parental to offspring's reading associations, we conducted path analyses, for which several model fit indices were examined: the chi-square $\left(\mathrm{X}^{2}\right)$, the Root Mean Square Error of Approximation (RMSEA), the Standardized Root Mean Square Residuals (SRMR), the goodness of fit index (GFI) and Bentler's Comparative Fit Index (CFI). A good fit is supported by an insignificant chisquare, RMSEA below 0.08 , SRMR below 0.09 and a value close to 0.95 for GFI and CFI 
(Barrett, 2007; Hu \& Bentler, 1999; van Bergen et al., 2015). Based on the correlational analyses, PA and RAN will be taken into account for the cognitive system and left IFOF for the neuroanatomical system as they correlate with both reading indices and family risk. Since the included cognitive and neuroanatomical measures correlated with parental reading and with the early reading score, we can infer that the additive model will likely have a poorer fit. Also, given that not all the variance in the early reading index was explained by the cognitive and neuroanatomical measures, a full mediated model is also less likely. Therefore, we first tested a partially mediated model in which parental influences (quantified by mothers' and fathers' self-reported reading skills, SES and HLE) impact children's early reading skills directly as well as indirectly via the neuroanatomical system that influences the cognitive system (see figure 1). The intermediate systems are ordered sequentially with the neuroanatomical system influencing the cognitive system (no relationships between parental influences and the cognitive system allowed). We first tested the model for early reading ability of the children indexed by letter knowledge in grade 1 (figure 3), followed by testing the same model for later reading ability of the children indexed by reading tests in grade 2 (figure 4 ).

Figure 3. The partial mediation model with standardized parameter estimates. The full lines represent direct links between parental influences and children's early reading index (LK) whereas the dotted lines represent indirect effects.

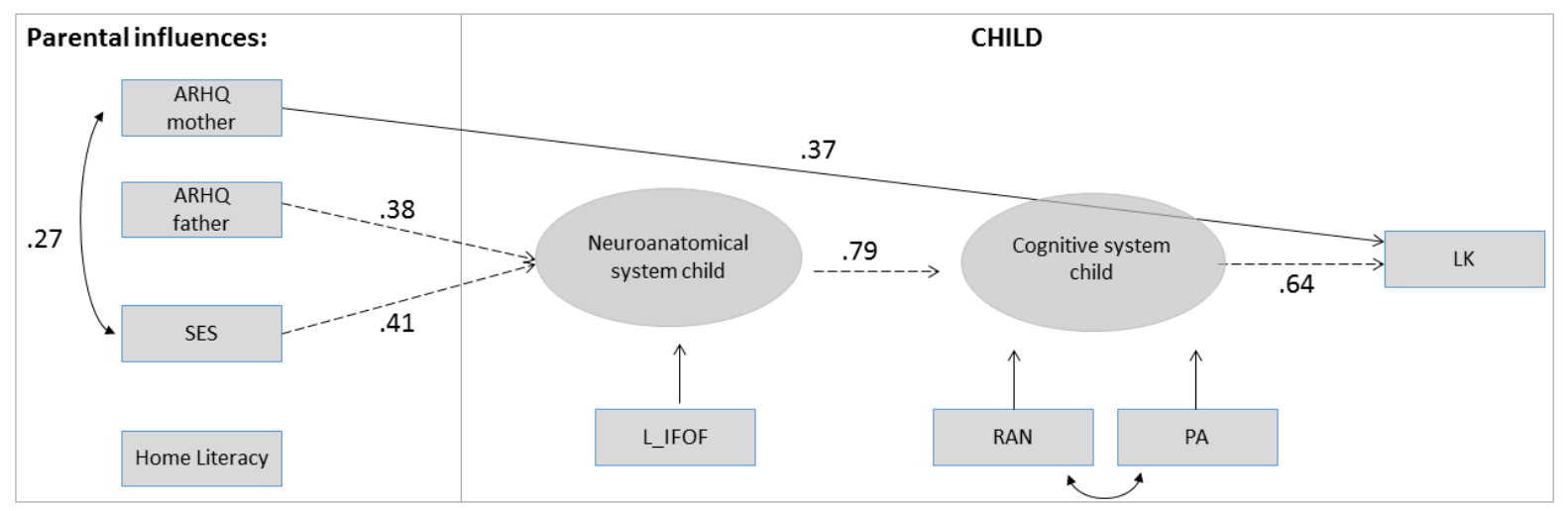

When modelling the link between parental influences and children's early reading index (i.e. LK in grade 1) (figure 3), the partial mediation model showed a good fit to the data $\left(X^{2}=19.95 ;\right.$ RMSEA $=0.13 ;$ SRMR = 0.07; GFI = 0.93; CFI = 0.88). SEM-analyses showed an influence of SES $(t=2.73 ; p=.006)$ and fathers' ARHQ $(t=2.34 ; p=.019)$ on children's left IFOF. Left IFOF influenced in turn the cognitive system of the children $(t=4.02 ; p<.001)$, which influenced the early reading skills of the children $(t=4.28 ; p<.001)$. The impact of fathers' reading on children's early reading was only indirect via the neuroanatomical and cognitive system, as no direct effect was found $(t=0.77 ; p=.441)$. In contrast, mothers' ARHQ did directly influence children's early reading scores $(t=3.47 ; p=.001)$ and showed no 
mediation via neuroanatomical system $(t=0.22 ; p=.830)$. A significant effect was also found between mothers' ARHQ and SES $(t=2.32 ; p=.020)$. No significant effects were found for home literacy environment (HLE).

When modelling the link between parental influences and children's reading scores in grade 2 (figure 4), the partial mediation model showed again a good fit to the data $\left(X^{2}=20.51\right.$; RMSEA $=0.13$; SRMR $=0.078 ; \mathrm{GFI}=0.93 ; \mathrm{CFI}=0.80)$. SEM-analyses showed again an influence of SES $(t=2.83 p=0.005)$ and fathers' ARHQ $(t=2.32 ; p=0.020)$ on children's left IFOF. Left IFOF influenced in turn the cognitive system of the children $(t=3.32 ; p<.001)$, which tended to influence the grade 2 skills of the children, though not significantly $(t=1.61 ; p$ $=.109$ ). This indicates that there is an indirect impact of father's self-reports of reading skills on children's grade 2 reading skills via the neuroanatomical and cognitive system of the children, but we additionally observed a direct effect of father's self-report of reading skills on children's grade 2 reading ( $t=2.20, p=.028$ ). Mothers' ARHQ also directly influenced children's grade 2 reading scores $(t=2.59 ; p=0.009)$ but there was again no mediation via the neuroanatomical system of the children $(t=-0.01 ; p=0.99)$. A significant effect was also found between mothers' ARHQ and SES $(t=2.25 ; p=0.025)$. No significant effects were found for home literacy environment. Hence, in the model both for children's early reading skills and for children's later reading skills the impact of father's reading on children's reading is mediated via children's left IFOF that in its turn influences the cognitive system, whereas mothers' reading skills influence children's reading skills directly.

Finally, we also tested the fully mediated model $\left(X^{2}=31.70\right.$; RMSEA $=0.14$; SRMR $=$ 0.08 ; $\mathrm{GFI}=0.72 ; \mathrm{CFI}=0.79)$ and the additive model $\left(X^{2}=35.11 ; \mathrm{RMSEA}=0.15 ; \mathrm{SRMR}=\right.$ $0.13 ; \mathrm{GFI}=0.89 ; \mathrm{CFI}=0.75$ ), but both resulted in a significantly poorer fit (Full mediated model: $\mathrm{X}^{2}=11.8 ; \mathrm{df}=4 ; p=0.019 ;$ Additive model: $\mathrm{X}^{2}=15.21 ; \mathrm{df}=4 ; p<0.01$ ).

Figure 4: The partial mediation model with standardized parameter estimates. The full lines represent direct links between parental influences and children's reading skills (composite reading score in grade 2) whereas the dotted lines represent indirect effects.

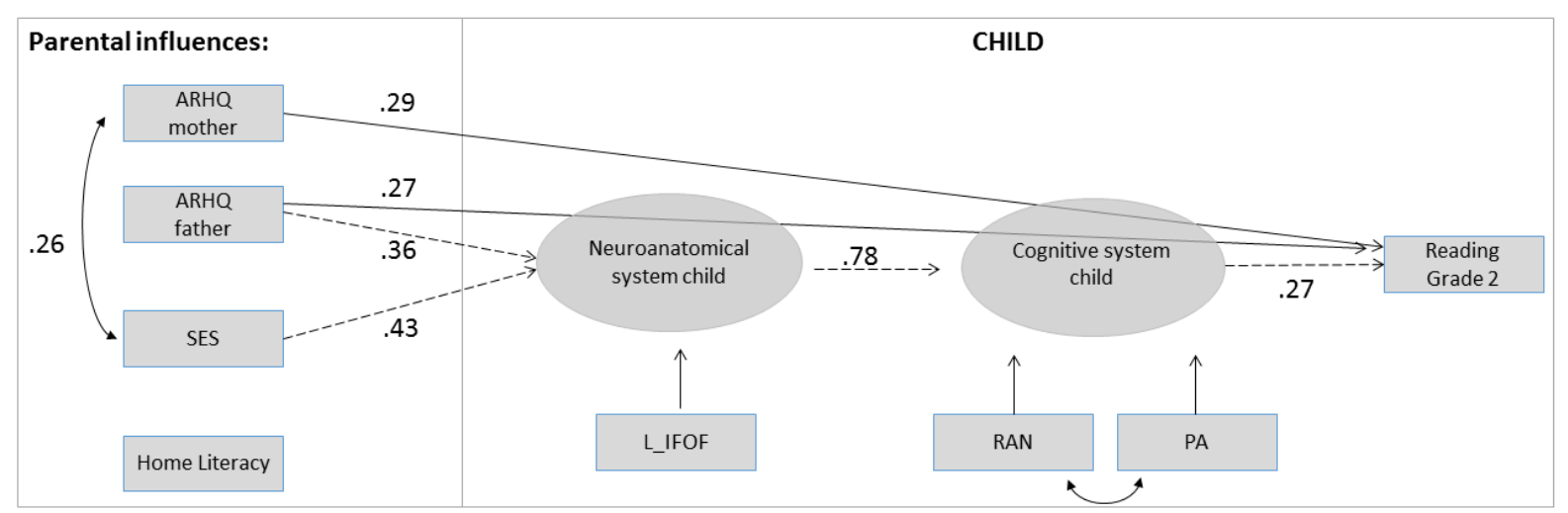




\section{Discussion}

The purpose of the study was to investigate which neuroanatomical and cognitive variables can mediate intergenerational transfer of reading skills. In an effort to take into account both the genetic and environmental parent-to-offspring contributions, we examined besides parental reading ability also the (reading) environment that parents provide for their children. Our results suggested that children's scores on PA and RAN and their white matter organization in left IFOF could be putative mediators since they correlated both with the reading scores of the children as well as of the parents. Path analyses, in which the interrelation between parental reading, environmental influences, children's reading ability and the putative mediators were simultaneously taken into account, demonstrated that both parents influence children's reading, but in fathers this is mediated via children's left ventral pathway (IFOF) whereas no mediation of white matter pathways is observed in mothers. In addition, also environmental factors, in particular SES, influence reading ability of the child via this ventral white matter pathway.

Regarding the mediation patterns for paternal reading, we see that for children's early reading skills (grade 1 ), the indirect pathway via IFOF and the cognitive system was the only association with paternal reading, but for later reading skills (grade 2) an additional direct pathway between paternal and offspring reading emerged. It might be that this direct pathway appears because later reading skills are increasingly determined by factors outside the neuroanatomical and cognitive system of the child, such as the type and amount of reading instruction and practice. Yet, it might also be that the appearance of the direct pathway is explained by the indirect pathway that becomes weaker for later reading skills. This indirect pathway might have been stronger when the neuroanatomical and cognitive system would have been assessed concurrent with the later reading skills in grade 2 instead of pre-reading. Note that the association between paternal reading and children's left IFOF was found in addition to environmental factors, namely SES, influencing left IFOF. This might suggest that the link between paternal reading and left IFOF is not driven by shared environmental factors but partly by genetic factors. Although our study is not designed to determine specific genetic contributions, there is a vast amount of evidence from other studies that indicates a dominant role for genes in the intergenerational transfer of reading skills. For example, we know from intergenerational studies that there is an association between parental and offspring reading data (e.g. van Bergen et al., 2015). This suggest a partly genetic contribution, especially since adoptive studies show no significant reading associations between a child and the nonbiological parent (Wadsworth, Corley, \& Hewitt, 2002). More direct evidence on genetic contributions is provided by twin studies which are designed to reveal the relative importance 
of environmental and genetic influences on a children's reading ability. Twin studies have demonstrated that most of the individual differences in reading are explained by genetic contributions, with a heritability rate of around $77 \%$ in Dutch speaking children (de Zeeuw, van Beijsterveldt, Glasner, de Geus, \& Boomsma, 2016) (for a meta-analysis across different contries see de Zeeuw, de Geus, \& Boomsma, 2015). Although one could assume -based on the intergenerational multiple deficit model (van Bergen, van der Leij, et al., 2014)- that genes also play a large role in the expression of the intermediate neural and cognitive system, very little direct evidence is available. Family risk studies, in which children with affected family members (often a parent) are compared to children with a low family risk on cognitive and neural measures, might provide a first hint on whether these intermediate levels are modulated by genetic factors. Several family risk studies have now shown that children with a high family risk consistently have phonological problems (for a review see Snowling \& Melby-Lervåg, 2016) and with the advent of MRI-studies in pre-readers with a family risk neuroanatomical deficits have recently also been shown (Raschle et al., 2011; Vandermosten et al., 2015) (for a review see Ozernov-Palchik \& Gaab, 2016; for a meta-analysis see Vandermosten et al., 2016). Hence, these family risk studies suggest a familial/parental effect on the cognitive and neuroanatomical system, although the genetic contribution is difficult to determine due to environmental factors that are closely intertwined in these family studies. At the neurobiological level, twin studies can again provide more direct evidence. For example, twins studies in which dMRI data were collected indicate that white matter pathways are indeed heritable (Chiang, McMahon, Zubicaray, \& Martin, 2011; Kochunov, Jahanshad, Marcus, \& Winkler, 2015). Yet, they also suggest that environmental factors can modulate the heritability of white matter, as heritability decreases with age due to environmental factors that start to dominate more at an older age (Chiang et al., 2011). Given that in our study white matter pathways are investigated in pre-readers, we could expect environmental factors to be less determining than later in reading development. However, we cannot exclude environmental effect since language and cognitive experiences in the first years of life, and even prenatally, will shape the reading underlying phonological mechanisms and the brain of the child. In that perspective, it is noteworthy that our result show that already in kindergarten an impact of SES on white matter was found. This corroborates and extends previous findings in school-aged children showing coherences between individual differences in SES and brain activation (K. Noble, Houston, \& Kan, 2012) and structure (Raizada, Richards, Meltzoff, \& Kuhl, 2008). Yet, above and beyond SES, paternal reading still significantly related to white matter organization in their children.

Of importance in discussing the mediating link between parental and offspring reading abilities via children's neuroanatomical and cognitive system is the observation that this 
mediating link was only found in the left ventral white matter pathway (IFOF) and only in fathers.

With regard to the location, our results indicate that the ventral pathway is a more dominant mediator than the dorsal pathway. First, this implies that the ventral pathway shows a stronger link with reading behavior than the dorsal pathway at the onset of reading. This is in contrast with standard model of Pugh et al. (2001) which suggests a dorsal involvement at the onset of reading acquisition and an increasing ventral involvement at more advanced stages of reading. Yet, our results are in line with empirical data from MRI studies at the onset of reading showing a widespread neural engagement instead of a specific dorsal involvement (for a review see Vandermosten et al., 2016). In addition, the model of Pugh et al. (2001) is mainly derived from English-based studies and might not generalize to more transparent orthographies like Dutch. An early ventral involvement, like we observed in Dutch-speaking children, is predicted by the recently proposed model of Richlan (2014) but cross-linguistic brain imaging studies across development are needed to shed more light on this. Second, this implies that the ventral pathway shows a stronger link than the dorsal pathway with parental reading. dMRI studies in twin adults showed high heritability of both $\mathrm{AF}_{\mathrm{FT}}$ and IFOF (Kochunov et al., 2015), hence providing no explanation for why family risk was only reflected in ventral and not in dorsal pathways in our study. However, longitudinal twin studies on reading have suggested that some reading-related genes share common variance with pre-reading phonological skills, whereas other genes only kick in after the start of reading acquisition (Byrne, Coventry, Olson, \& Samuelsson, 2009; Christopher, Hulslander, \& Byrne, 2015). Given that these different type of genes might have a different neurobiological location of expression, one hypothetic explanation for finding especially parental effects on left IFOF might be that the genes related to pre-reading skills are expressed in ventral regions while genes related to later reading skills are expressed in dorsal regions. Whether these different types of genes have a dorsal versus ventral place of expression remains to be investigated, yet it would fit with the findings that in adults literacy-related genes are expressed in dorsal regions (Darki, PeyrardJanvid, \& Matsson, 2014) and in pre- to beginning readers in ventral regions (Skeide et al., 2016).

With regard to the paternal influences in absence of maternal influences on the white matter in our pre-reading sample, several hypothetical explanations might be proposed. First, maternal influences on white matter might be present, but only expressed at a different point in development. However, a study by Black et al. (2012) indicates maternal influences on the brain already at the very beginning of reading development, which is similar to the age range of our sample. Although that study focuses on grey matter volume instead of white matter microstructure as in our study, it seems to reject the hypothesis that maternal influences on 
the brain are not expressed at the start of reading acquisition. An alternative explanation might be that the fathers in our sample were slightly more affected by dyslexia $(58 \%)$ than the mothers were (47\%). Although the intergenerational multiple deficit model suggests that both the affected and unaffected parent contribute to the different levels of the child's reading system, having a higher liability for reading problems might result in more pronounced white matter differences in the child. Finally, a last explanation is that mothers do impact children's white matter but that mothers' genetic and environmental influences are too closely intertwined to see independent contributions. Mothers generally spend more time with their children especially regarding school-related activities and our path analyses results indeed indicate a closer relationship with environmental factors in mothers than in fathers.

Finally, the observation that PA, RAN and left IFOF not only correlate with child's reading skills but also with some of the reading indices of the parents, representing the family risk for dyslexia, might provide more insight in defining these variables as endophenotypes. According to Bearden and Freimer (2006), an endophenotype should (a) be associated with the disorder in the population; (b) be heritable and run within families; and (c) be stateindependent. Although we used a continuous approach which obstructs a direct application of the definition of Bearden and Freimer, our correlational results might suggest that PA, RAN and left IFOF could be considered as endophenotypes. In a recent study by Moll et al (2013) who used a group-based approach and demonstrated that phonological skills are associate both with dyslexia diagnosis and with the family risk for dyslexia, phonological skills are also considered as cognitive endophenotype. Future studies that use a dyslexia and family risk group classification should evaluate whether left IFOF can indeed be considered as a neural endophenotype, like our results suggest. Note, however that the observed association between FA of the left IFOF and reading of parents and children are weak and warrant cautious in defining them as endophenotypes.

To conclude, path analyses showed that paternal reading skills indirectly predict early reading (indexed by letter knowledge) and later reading of the child through left IFOF, a ventral white matter pathway, whereas mothers influence a child's reading abilities more directly, with no mediating role of white matter pathways. Given that this indirect pathway in fathers is present in addition to environmental factors influencing this white matter pathway, a tentative interpretation is that coherences between paternal and offspring reading are partly genetically driven. 


\section{Acknowledgements}

This research was funded by the Research Council of KU Leuven (OT/12/044) and the Research Foundation Flanders (G0920.12) Maaike Vandermosten is postdoctoral fellow of the Research Foundation Flanders. Sophie Dandache, Sophie Vanvooren, Catherine Theys and Astrid De Vos are gratefully acknowledged for assistance in participant selection and data collection. 


\section{References}

Barrett, P. (2007). Structural equation modelling: Adjudging model fit. Personality and Individual Differences, 42(5), 815-824.

Bearden, C., \& Freimer, N. (2006). Endophenotypes for psychiatric disorders: ready for primetime? Trends in Genetics, 22(6), 306-13.

Bergen, E. van, Jong, P. de, \& Plakas, A. (2012). Child and parental literacy levels within families with a history of dyslexia. Journal of Child Psychology and Psychiatry, 53(1), 28-36.

Bergen, E. van, Jong, P. de, Regtvoort, A., \& Oort, F. (2011). Dutch children at family risk of dyslexia: Precursors, reading development, and parental effects.Dyslexia, 17(1), 2-18.

Black, J. M., Tanaka, H., Stanley, L., Nagamine, M., Zakerani, N., Thurston, A., ... Hoeft, F. (2012b). Maternal history of reading difficulty is associated with reduced language-related gray matter in beginning readers. NeuroImage, 59(3), 3021-32.

Boets, B., Smedt, B., Cleuren, L., Vandewalle, E., Wouters, J., \& Ghesquière, P. (2010). Towards a further characterization of phonological and literacy problems in Dutch-speaking children with dyslexia. British Journal of Developmental Psychology, 28(1), 5-31.

Boudreau, B., \& Poulin, C. (2009). An examination of the validity of the Family Affluence Scale II (FAS II) in a general adolescent population of Canada. Social Indicators Research, 94: 29.

Boyce, W., Torsheim, T., Currie, C., \& Zambon, A. (2006). The family affluence scale as a measure of national wealth: validation of an adolescent self-report measure. Social Indicators Research, 78(3), 473-487.

Brus, B. T., \& Voeten, M. J. (1973). Eén Minuut Test: verantwoording en handleiding [One Minute Test: Manual]. Nijmegen: Berkhout.

Byrne, B., Coventry, W., Olson, R., \& Samuelsson, S. (2009). Genetic and environmental influences on aspects of literacy and language in early childhood: Continuity and change from preschool to Grade 2. Journal of Neurolinguistics, 22(3), 219-236.

Catani, M., \& Thiebaut de Schotten, M. (2012). Atlas of human brain connections. Oxford: Oxford University Press.

Chiang, M., McMahon, K., Zubicaray, G. de, \& Martin, N. (2011). Genetics of white matter development: a DTI study of 705 twins and their siblings aged 12 to 29. Neuroimage, 54(3), 230817.

Christopher, M., Hulslander, J., \& Byrne, B. (2015). Genetic and environmental etiologies of the longitudinal relations between prereading skills and reading. Child Development, 82(2), 342-61.

Darki, F., Peyrard-Janvid, M., \& Matsson, H. (2014). DCDC2 polymorphism is associated with left temporoparietal gray and white matter structures during development. The Journal of Neuroscience, 34(43), 14455-62.

de Jong, P. De, Seveke, M., \& Veen, M. van. (2000). Phonological sensitivity and the acquisition of new words in children. Journal of Experimental Child Psychology, 776(4), 275-301.

de Zeeuw, E. L., de Geus, E. J. C., \& Boomsma, D. I. (2015). Meta-analysis of twin studies highlights the importance of genetic variation in primary school educational achievement. Trends in Neuroscience and Education, 4(3), 69-76. 1

de Zeeuw, E. L., van Beijsterveldt, C. E. M., Glasner, T. J., de Geus, E. J. C., \& Boomsma, D. I. (2016). Arithmetic, reading and writing performance has a strong genetic component: A study in primary school children. Learning and Individual Differences, 47, 156-166.

Gullick, M., \& Booth, J. (2014). Individual differences in crossmodal brain activity predict arcuate 
fasciculus connectivity in developing readers. Journal of Cognitive Neuroscience, 26(7), 1331-46.

Hosseini, S. M. H., Black, J. M., Soriano, T., Bugescu, N., Martinez, R., Raman, M. M., ... Hoeft, F. (2013). Topological properties of large-scale structural brain networks in children with familial risk for reading difficulties. NeuroImage, 71, 260-74.

Hu, L., \& Bentler, P. (1999). Cutoff criteria for fit indexes in covariance structure analysis: Conventional criteria versus new alternatives. Structural Equation Modeling: A Multidisciplinary Journal, 6(1), $1-55$.

Im, K., Raschle, N. M., Smith, S. A., Ellen Grant, P., \& Gaab, N. (2016). Atypical Sulcal Pattern in Children with Developmental Dyslexia and At-Risk Kindergarteners. Cerebral Cortex, 26(3), 1138-48.

Kochunov, P., Jahanshad, N., Marcus, D., \& Winkler, A. (2015). Heritability of fractional anisotropy in human white matter: a comparison of Human Connectome Project and ENIGMA-DTI data. Neuroimage, 111, 300-11.

Leemans, A., Jeurissen, B., Sijbers, J., \& Jones, D. (2009). ExploreDTI: a graphical toolbox for processing, analyzing, and visualizing diffusion MR data. In 17th Annual Meeting of Intl Soc Mag Reson Med (p. 3537). Hawaii.

Lefly, D. L., \& Pennington, B. F. (2000). Reliability and validity of the adult reading history questionnaire. Journal of Learning Disabilities, 33(3), 286-96.

Molfese, V., Modglin, A., \& Molfese, D. (2003). The Role of Environment in the Development of Reading Skills A Longitudinal Study of Preschool and School-Age Measures. Journal of Learning Disabilities, 36(1), 59-67.

Moll, K., Loff, A., \& Snowling, M. J. (2013). Cognitive Endophenotypes of Dyslexia. Scientific Studies of Reading, 17(6), 385-397.

Myers, C. A., Vandermosten, M., Farris, E. A., Hancock, R., Gimenez, P., Black, J. M., ... Hoeft, F. (2014). White matter morphometric changes uniquely predict children's reading acquisition. Psychological Science, 25(10), 1870-83.

Nakagawa, S. (2004). A farewell to Bonferroni: the problems of low statistical power and publication bias. Behavioral Ecology, 15(6), 1044-1045.

Niklas, F., \& Schneider, W. (2013). Home Literacy Environment and the beginning of reading and spelling. Contemporary Educational Psychology, 38(1), 40-50.

Noble, K. G., Wolmetz, M. E., Ochs, L. G., Farah, M. J., \& McCandliss, B. D. (2006). Brain-behavior relationships in reading acquisition are modulated by socioeconomic factors. Developmental Science, 9(6).

Noble, K., Houston, S., \& Kan, E. (2012). Neural correlates of socioeconomic status in the developing human brain. Developmental Science, 15(4), 516-27.

Nuytten, S. (2005). Vragenlijst leeservaring van volwassenen: een vertaling van de "Adult Reading History Questionnaire" (Unpublished master's thesis). KU Leuven.

Odegard, T., Farris, E., Ring, J., McColl, R., \& Black, J. (2009). Brain connectivity in non-reading impaired children and children diagnosed with developmental dyslexia. Neuropsychologia, 47(8), $1972-7$.

Olson, R., Keenan, J., \& Byrne, B. (2014). Why do children differ in their development of reading and related skills? Scientific Studies of Reading, 18(1), 38-54.

Ozernov-Palchik, O., \& Gaab, N. (2016). Tackling the "dyslexia paradox": reading brain and behavior for early markers of developmental dyslexia. WIREs Cognitive Science, 7, 156-176.

Paulesu, E., Danelli, L., \& Berlingeri, M. (2014). Reading the dyslexic brain: multiple dysfunctional 
routes revealed by a new meta-analysis of PET and fMRI activation studies. Frontiers in Human Neuroscience, 8,830 .

Pennington, B. F., Santerre-Lemmon, L., Rosenberg, J., MacDonald, B., Boada, R., Friend, A., ... Olson, R. K. (2012). Individual prediction of dyslexia by single versus multiple deficit models. Journal of Abnormal Psychology, 121(1), 212-24.

Peterson, R. L., \& Pennington, B. F. (2015). Developmental dyslexia. Annual Review of Clinical Psychology, 11, 283-307.

Pugh, K. R., Mencl, W. E., Jenner, A. R., Katz, L., Frost, S. J., Lee, J. R., ... Shaywitz, B. A. (2001). Neurobiological studies of reading and reading disability. Journal of Communication Disorders, 34(6), 479-492.

Raizada, R., Richards, T., Meltzoff, A., \& Kuhl, P. (2008). Socioeconomic status predicts hemispheric specialisation of the left inferior frontal gyrus in young children. Neuroimage, 40(3), 1392-401.

Raschle, N. M., Chang, M., \& Gaab, N. (2011). Structural brain alterations associated with dyslexia predate reading onset. NeuroImage, 57(3), 742-9.

Raschle, N. M., Stering, P. L., Meissner, S. N., \& Gaab, N. (2014). Altered neuronal response during rapid auditory processing and its relation to phonological processing in prereading children at familial risk for dyslexia. Cerebral Cortex (New York, N.Y. : 1991), 24(9), 2489-501.

Raschle, N. M., Zuk, J., \& Gaab, N. (2012). Functional characteristics of developmental dyslexia in lefthemispheric posterior brain regions predate reading onset. Proceedings of the National Academy of Sciences of the United States of America, 109(6), 2156-61.

Raven, J. C., Court, J. H., \& Raven, J. (1984). Manual for Ravens's Progressive Matrices and Vocabulary Scales. London: Lewis.

Richlan, F. (2014). Functional neuroanatomy of developmental dyslexia: the role of orthographic depth. Frontiers in Human Neuroscience, 8, 347.

Richlan, F., Kronbichler, M., \& Wimmer, H. (2009). Functional abnormalities in the dyslexic brain: a quantitative meta-analysis of neuroimaging studies. Human Brain Mapping, 30(10), 3299-308.

Richlan, F., Kronbichler, M., \& Wimmer, H. (2013). Structural abnormalities in the dyslexic brain: a meta-analysis of voxel-based morphometry studies. Human Brain Mapping, 34(11), 3055-65.

Rimrodt, S., Peterson, D., Denckla, M., \& Kaufmann, W. (2010). White matter microstructural differences linked to left perisylvian language network in children with dyslexia. Cortex, 46(6), $739-49$.

Saygin, Z. M., Norton, E. S., Osher, D. E., Beach, S. D., Cyr, A. B., Ozernov-Palchik, O., ... Gabrieli, J. D. E. (2013). Tracking the roots of reading ability: white matter volume and integrity correlate with phonological awareness in prereading and early-reading kindergarten children. The Journal of Neuroscience : The Official Journal of the Society for Neuroscience, 33(33), 13251-8.

Scerri, T., \& Schulte-Körne, G. (2010). Genetics of developmental dyslexia. European Child \& Adolescent Psychiatry, 14(6), 681-9.

Sénéchal, M., \& LeFevre, J. (2002). Parental involvement in the development of children's reading skill: A five-year longitudinal study. Child Development, 73(2), 445-60.

Silinskas, G., Lerkkanen, M., Tolvanen, A., \& Niemi, P. (2012). The frequency of parents' readingrelated activities at home and children's reading skills during kindergarten and Grade 1. Journal of Applied Developmental Psychology, 33(6), 302-10.

Skeide, M. A., Kraft, I., Mü, B., Schaadt, G., Neef, N. E., Brauer, J., ... Friederici, A. D. (2016). NRSN1 associated grey matter volume of the visual word form area reveals dyslexia before school. BRAIN, $139,2792-2803$. 
Snowling, M. (2000). Dyslexia . Retrieved from http://psycnet.apa.org/psycinfo/2000-12298-000

Snowling, M. J., \& Melby-Lervåg, M. (2016). Oral Language Deficits in Familial Dyslexia: A MetaAnalysis and Review. Psychological Bulletin, 142(5), 498-545.

Snowling, M., Muter, V., \& Carroll, J. (2007). Children at family risk of dyslexia: a follow-up in early adolescence. Journal of Child Psychology, 48(6), 609-18.

Steinbrink, C., Vogt, K., Kastrup, A., \& Müller, H. (2008). The contribution of white and gray matter differences to developmental dyslexia: insights from DTI and VBM at 3.0 T. Neuropsychologia, 46(13), 3170-8.

Theys, C., Wouters, J., \& Ghesquière, P. (2014). Diffusion tensor imaging and resting-state functional MRI-scanning in 5- and 6-year-old children: training protocol and motion assessment. PloS One, 9(4), e94019.

Torppa, M., Poikkeus, A., \& Laakso, M. (2006). Predicting delayed letter knowledge development and its relation to grade 1 reading achievement among children with and without familial risk for dyslexia. Developmental Psychology, 42(6), 1128-42.

Torppa, M., Poikkeus, A., \& Laakso, M. (2007). Modeling the early paths of phonological awareness and factors supporting its development in children with and without familial risk of dyslexia. Scientific Studies of Reading, 11, 73-103.

van Bergen, E., Bishop, D., van Zuijen, T., \& de Jong, P. F. (2015). How Does Parental Reading Influence Children's Reading? A Study of Cognitive Mediation. Scientific Studies of Reading, 19(5), 325-339.

van Bergen, E., de Jong, P. F., Maassen, B., \& van der Leij, A. (2014). The effect of parents' literacy skills and children's preliteracy skills on the risk of dyslexia. Journal of Abnormal Child Psychology, 42(7), 1187-200.

van Bergen, E., van der Leij, A., \& de Jong, P. F. (2014). The intergenerational multiple deficit model and the case of dyslexia. Frontiers in Human Neuroscience, 8, 346.

van den Bos, K. P., Spelberg, H. C. L., Scheepstra, A. J. ., \& de Vries, J. R. (1994). De Klepel. Vorm A en B. Een test voor leesvaardigheid van pseudowoorden. Verantwoording, handleiding, diagnostiek en behandeling [Word and non word reading test $A \& B$ manual]. Nijmegen: Berkhout.

van den Bos, K., \& Zijlstra, B. (2002). Life-span data on continuous-naming speeds of numbers, letters, colors, and pictured objects, and word-reading speed. Scientific Studies of Reading, 6, 25-49.

Vanderauwera, J., Vandermosten, M., Dell'Acqua, F., Wouters, J., \& Ghesquière, P. (2015). Disentangling the relation between left temporoparietal white matter and reading: A spherical deconvolution tractography study. Human Brain Mapping, 36(8), 3273-87.

Vandermosten, M., Boets, B., Poelmans, H., Sunaert, S., Wouters, J., \& Ghesquière, P. (2012). A tractography study in dyslexia: Neuroanatomic correlates of orthographic, phonological and speech processing. Brain, 135(3), 935-948.

Vandermosten, M., Hoeft, F., \& Norton, E. S. (2016). Integrating MRI brain imaging studies of prereading children with current theories of developmental dyslexia: A review and quantitative metaanalysis. Current Opinion in Behavioral Science, 10, 155-161.

Vandermosten, M., Vanderauwera, J., Theys, C., De Vos, A., Vanvooren, S., Sunaert, S., ... Ghesquière, P. (2015). A DTI tractography study in pre-readers at risk for dyslexia. Developmental Cognitive Neuroscience, 14, 8-15. https://doi.org/10.1016/j.den.2015.05.006

Vellutino, F. R., Fletcher, J. M., Snowling, M. J., \& Scanlon, D. M. (2004). Specific reading disability (dyslexia): what have we learned in the past four decades? Journal of Child Psychology and Psychiatry, 45(1), 2-40. 
Verhoeven, L. (2002). Passieve letterkennis [Receptive letter knowledge]. Arnhem: Cito.

Wadsworth, S. J., Corley, R. P., Hewitt, J. K., Plomin, R., \& DeFries, J. C. (2002). Parent-offspring resemblance for reading performance at 7, 12 and 16 years of age in the Colorado Adoption Project. Journal of Child Psychology and Psychiatry, 43(6), 769-74.

Wakana, S., Caprihan, A., Panzenboeck, M. M., Fallon, J. H., Perry, M., Gollub, R. L., ... Mori, S. (2007). Reproducibility of quantitative tractography methods applied to cerebral white matter. NeuroImage, 36(3), 630-44.

Yeatman, J. D., Dougherty, R. F., Rykhlevskaia, E., Sherbondy, A. J., Deutsch, G. K., Wandell, B. A., $\&$ Ben-Shachar, M. (2011). Anatomical properties of the arcuate fasciculus predict phonological and reading skills in children. Journal of Cognitive Neuroscience, 23(11), 3304-17.

\section{Figure Legends}

Figure 1. Representation of the three different models. The blue and orange arrows indicate the relationships that could disappear respectively in the full mediated model and the additive model. The full lines represent direct links between parental influences and child's reading whereas the dotted lines represent indirect effects.

Figure 2. DTI tractography of the direct segment of the left arcuate fasciculus (AFFT) and the left inferior fronto-occipital fasciculus (IFOF). The right IFOF is also included in the analyses but is not depicted in the figure. The right AFFT is not included in the analyses since it could only be delineated in $70 \%$ of the subjects.

Figure 3. The partial mediation model with standardized parameter estimates. The full lines represent direct links between parental influences and children's early reading index (LK) whereas the dotted lines represent indirect effects.

Figure 4: The partial mediation model with standardized parameter estimates. The full lines represent direct links between parental influences and children's reading skills (composite reading score in grade 2) whereas the dotted lines represent indirect effects.

\section{Table Legends}

Table 1: Descriptive statistics of children's and parental cognitive and reading skills and children's neuroanatomical measures

Table 2: Correlations between children's cognitive and neuroanatomical measures on the one hand children's and parental reading data on the other hand

Table SI: Pearson and Spearman (italic) correlations between children's early reading index, children's cognitive and neuroanatomical measures and parental reading skills 


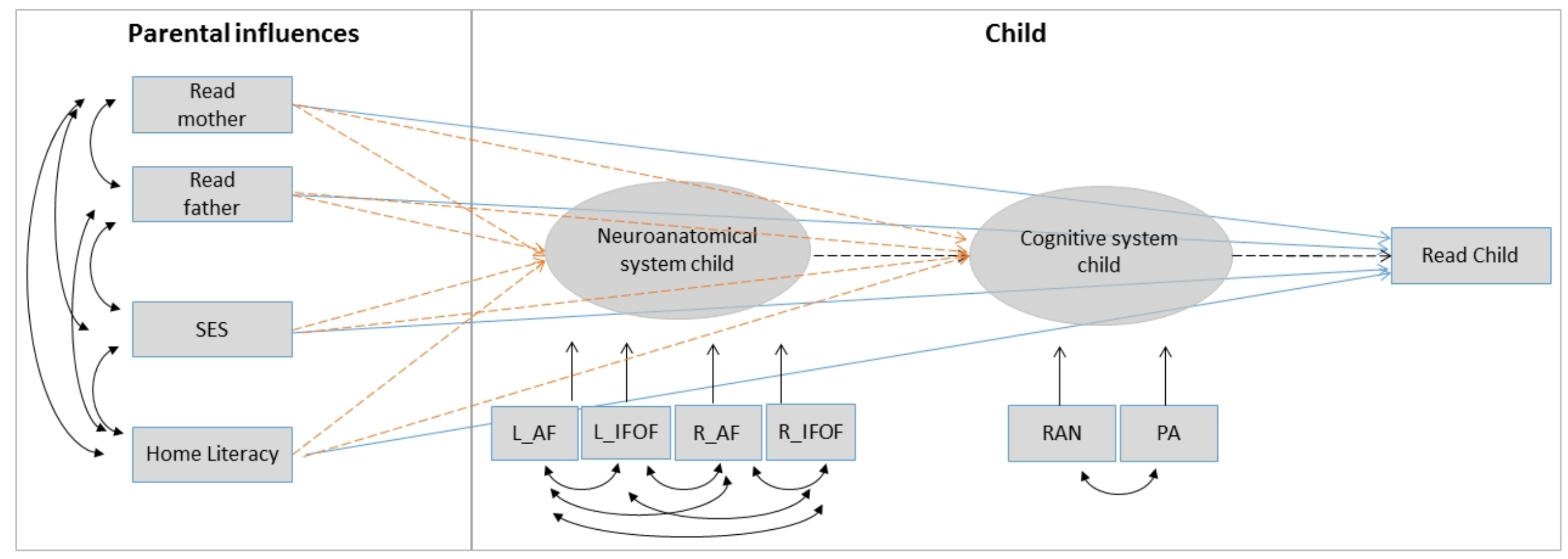




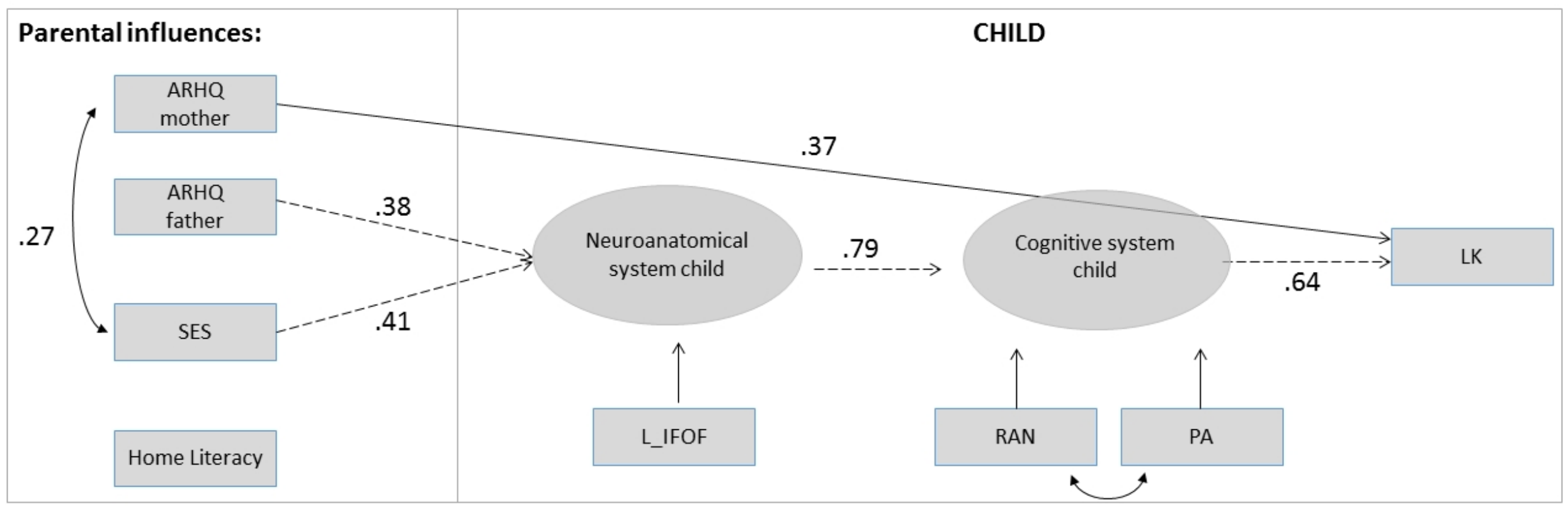




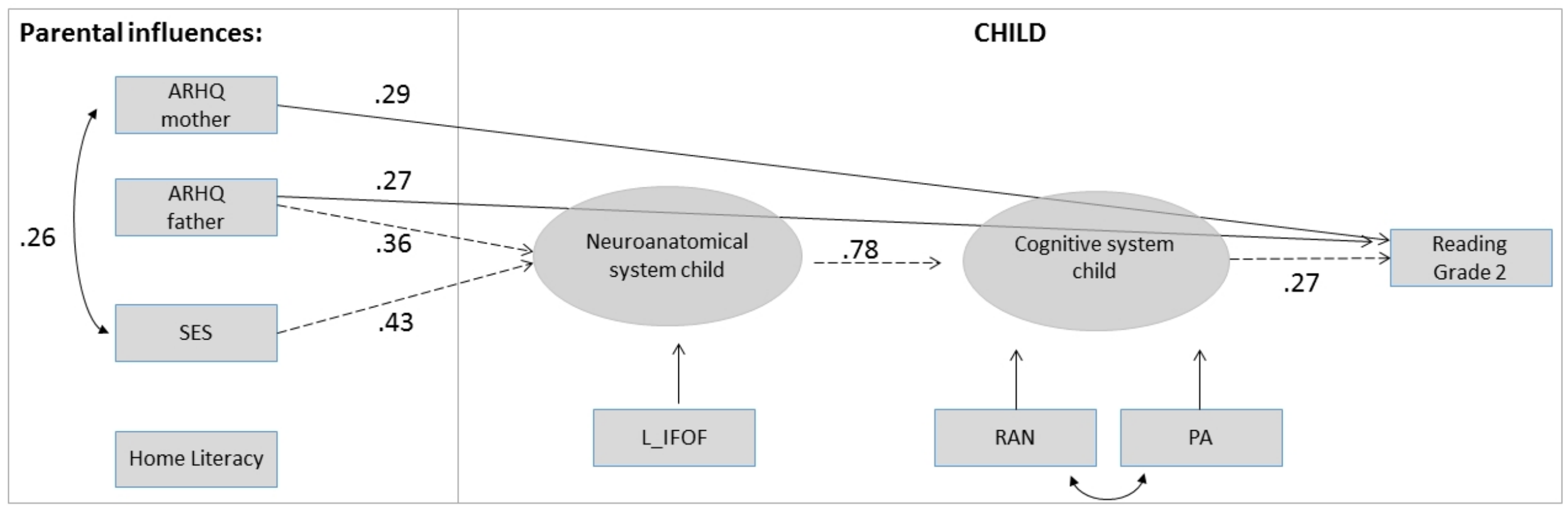




\begin{tabular}{|c|c|c|c|c|c|c|c|c|c|c|c|c|c|}
\hline & 1. & 2. & 3. & 4. & 5. & 6. & 7. & 8. & 9. & 10. & 11. & 12. & 13. \\
\hline 1. $\mathrm{PA}$ & $\begin{array}{c}1 \\
71\end{array}$ & & & & & & & & & & & & \\
\hline 2. RAN & $\begin{array}{c}.357^{\star *} \\
.002 \\
71\end{array}$ & $\begin{array}{c}1 \\
71\end{array}$ & & & & & & & & & & & \\
\hline 3. LK & $\begin{array}{c}.439^{\star *} \\
.000 \\
71\end{array}$ & $\begin{array}{c}.492^{\star *} \\
.000 \\
71\end{array}$ & $\begin{array}{c}1 \\
71\end{array}$ & & & & & & & & & & \\
\hline 4. Right AF & $\begin{array}{c}.253 \\
.077 \\
50\end{array}$ & $\begin{array}{c}.105 \\
.468 \\
50\end{array}$ & $\begin{array}{c}.235 \\
.100 \\
50\end{array}$ & $\begin{array}{c}1 \\
50\end{array}$ & & & & & & & & & \\
\hline 5. Left AF & $\begin{array}{l}.296^{*} \\
.012 \\
71\end{array}$ & $\begin{array}{l}.178 \\
.138 \\
71\end{array}$ & $\begin{array}{c}.203 \\
.090 \\
71\end{array}$ & $\begin{array}{c}.504^{\star *} \\
.000 \\
50\end{array}$ & $\begin{array}{c}1 \\
71\end{array}$ & & & & & & & & \\
\hline 6. Right IFOF & $\begin{array}{c}.375^{\star \star} \\
.001 \\
71\end{array}$ & $\begin{array}{c}.311^{\star *} \\
.008 \\
71\end{array}$ & $\begin{array}{l}.276^{*} \\
.020 \\
71\end{array}$ & $\begin{array}{c}.393^{\star \star} \\
.005 \\
50\end{array}$ & $\begin{array}{l}.454^{\star *} \\
.000 \\
71\end{array}$ & $\begin{array}{c}1 \\
71\end{array}$ & & & & & & & \\
\hline 7. Left IFOF & $\begin{array}{c}.362^{\star *} \\
.002 \\
71\end{array}$ & $\begin{array}{c}.189 \\
.114 \\
71\end{array}$ & $\begin{array}{l}.263^{*} \\
.026 \\
71\end{array}$ & $\begin{array}{c}.556^{\star *} \\
.000 \\
50\end{array}$ & $\begin{array}{l}.479^{\star *} \\
.000 \\
71\end{array}$ & $\begin{array}{l}.659 * * \\
.000 \\
71\end{array}$ & $\begin{array}{c}1 \\
71\end{array}$ & & & & & & \\
\hline 8. Reading tests mother & $\begin{array}{c}.096 \\
.481 \\
56\end{array}$ & $\begin{array}{c}.384^{\star *} \\
.003 \\
56\end{array}$ & $\begin{array}{c}.450 * * \\
.001 \\
56\end{array}$ & $\begin{array}{c}.120 \\
.466 \\
39\end{array}$ & $\begin{array}{c}-.005 \\
.968 \\
56\end{array}$ & $\begin{array}{c}-.009 \\
.950 \\
56\end{array}$ & $\begin{array}{c}-.010 \\
.941 \\
56\end{array}$ & $\begin{array}{c}1 \\
56\end{array}$ & & & & & \\
\hline 9. Reading tests father & $\begin{array}{c}.427^{\star} \\
.015 \\
32\end{array}$ & $\begin{array}{c}.409 * \\
.020 \\
32\end{array}$ & $\begin{array}{c}.294 \\
.103 \\
32\end{array}$ & $\begin{array}{l}.102 \\
.629 \\
25\end{array}$ & $\begin{array}{c}.125 \\
.497 \\
32\end{array}$ & $\begin{array}{l}.005 \\
.977 \\
32\end{array}$ & $\begin{array}{c}.038 \\
.835 \\
32\end{array}$ & $\begin{array}{c}.272 \\
.247 \\
20\end{array}$ & $\begin{array}{c}1 \\
32\end{array}$ & & & & \\
\hline 10. ARHQ mother & $\begin{array}{c}-.042 \\
.737 \\
66\end{array}$ & $\begin{array}{c}-.398^{\star \star} \\
.001 \\
66\end{array}$ & $\begin{array}{c}-.407^{\star *} \\
.001 \\
66\end{array}$ & $\begin{array}{c}-.035 \\
.816 \\
46\end{array}$ & $\begin{array}{c}.138 \\
.268 \\
66\end{array}$ & $\begin{array}{c}-.031 \\
.807 \\
66\end{array}$ & $\begin{array}{c}.023 \\
.853 \\
66\end{array}$ & $\begin{array}{c}-.412^{* *} \\
.002 \\
53\end{array}$ & $\begin{array}{c}-.096 \\
.606 \\
31\end{array}$ & $\begin{array}{c}1 \\
66\end{array}$ & & & \\
\hline 11. ARHQ father & $\begin{array}{c}-.257^{*} \\
.040 \\
64\end{array}$ & $\begin{array}{c}-.126 \\
.320 \\
64\end{array}$ & $\begin{array}{c}-.202 \\
.110 \\
64\end{array}$ & $\begin{array}{c}-.198 \\
.188 \\
46\end{array}$ & $\begin{array}{c}-.099 \\
.437 \\
64\end{array}$ & $\begin{array}{c}-.027 \\
.831 \\
64\end{array}$ & $\begin{array}{c}-.295^{*} \\
.018 \\
64\end{array}$ & $\begin{array}{c}-.005 \\
.973 \\
50\end{array}$ & $\begin{array}{c}-.609 * * \\
.000 \\
31\end{array}$ & $\begin{array}{c}-.167 \\
.199 \\
61\end{array}$ & $\begin{array}{c}1 \\
64\end{array}$ & & \\
\hline 12. Home literacy environment & $\begin{array}{c}-.022 \\
.865 \\
62\end{array}$ & $\begin{array}{c}-.022 \\
.865 \\
62\end{array}$ & $\begin{array}{c}.228 \\
.074 \\
62\end{array}$ & $\begin{array}{c}.385^{\star} \\
.011 \\
43\end{array}$ & $\begin{array}{l}.052 \\
.686 \\
62\end{array}$ & $\begin{array}{l}.060 \\
.642 \\
62\end{array}$ & $\begin{array}{l}.292^{\star} \\
.021 \\
62\end{array}$ & $\begin{array}{c}.300^{*} \\
.034 \\
50\end{array}$ & $\begin{array}{c}-.207 \\
.281 \\
29\end{array}$ & $\begin{array}{c}-.226 \\
.088 \\
58\end{array}$ & $\begin{array}{c}-.027 \\
.842 \\
56\end{array}$ & $\begin{array}{c}1 \\
62\end{array}$ & \\
\hline 13. Reading grade 2 & $\begin{array}{c}.330^{* *} \\
.005 \\
71\end{array}$ & $\begin{array}{c}.423^{\star *} \\
.000 \\
71\end{array}$ & $\begin{array}{l}.424^{* *} \\
.000 \\
71\end{array}$ & $\begin{array}{c}.285^{\star} \\
.045 \\
50\end{array}$ & $\begin{array}{l}.184 \\
.125 \\
71\end{array}$ & $\begin{array}{l}.127 \\
.292 \\
71\end{array}$ & $\begin{array}{c}.177 \\
.140 \\
71\end{array}$ & $\begin{array}{c}.613^{\star *} \\
.000 \\
56\end{array}$ & $\begin{array}{c}.535^{\star *} \\
.002 \\
32\end{array}$ & $\begin{array}{c}-.209 \\
.092 \\
66\end{array}$ & $\begin{array}{c}-.354^{* *} \\
.005 \\
63\end{array}$ & $\begin{array}{c}.172 \\
.180 \\
62\end{array}$ & $\begin{array}{c}1 \\
71\end{array}$ \\
\hline
\end{tabular}




\section{Highlights}

- Parental reading relates to offspring's white matter (WM) and phonological skills

- Fathers' reading and SES influence children's early reading via ventral WM

- Mothers display no mediating role via WM

- SES relates to children's early reading via WM and to mothers' reading

- Parent-offspring associations might be partly genetically driven 